\title{
Stabilization of High Molecular Weight Nylon 6 Synthesized by Anionic Polymerization of $\varepsilon$-Caprolactam
}

\author{
Kazue Ueda, Makoto NaKaI, Masahiro Hosoda, and Kazuo TaI \\ Research \& Development Center, UNITIKA Ltd., 23 Kozakura, Uji, Kyoto, 611, Japan
}

(Received May 23, 1996)

\begin{abstract}
To stablilize high-molecular weight nylon 6 synthesized by the anionic polymerization of $\varepsilon$-caprolactam, a method to prevent polymer degradation by removing catalyst residue was investigated. The removal of catalyst residue in the polymer was efficiently carried out by treating with acids whose $\mathrm{p} K_{\mathrm{a}}$ in water were between 3 and 7 . The stability of the polymer on heating at $200^{\circ} \mathrm{C}$ in vacuo was highly improved by removing the catalyst residue with treatment by acetic acid $\left(\mathrm{p} K_{\mathrm{a}}=4.8\right)$ in dimethyl sulfoxide solution. The reached weight average molecular weights $\left(M_{w}\right)$ on heating at $200^{\circ} \mathrm{C}$ were $6.0 \times 10^{4}$ (initial $M_{w}=6.2 \times 10^{4}$ ), and $3.9 \times 10^{5}$ (initial $M_{w}=7.0 \times 10^{5}$ ). The decrease of $M_{w}$ of the high molecular weight polymer without the catalyst residue on heating is considered due to hydrolysis, because the change of $M_{w}$ agrees with the simulation results based on the assumption that decrease of the molecular weight is caused by hydrolysis. Hydrolysis was negligibly influenced by the catalytic activity of the terminal carboxyl group (provided the terminal concentration less than $0.07 \mathrm{~mol} \%$ ).
\end{abstract}

KEY WORDS Stabilization/Nylon 6/Anionic Polymerization / $\varepsilon$-Caprolactam/High Molecular Weight/

Catalyst Residue / Hydrolysis /

The anionic polymerization of $\varepsilon$-caprolactam has been extensively investigated because of the high yield and rate of polymerization. ${ }^{1-4}$ Fundamental characters such as various catalysts, ${ }^{2,5,6}$ propagation mechanism, ${ }^{7-10}$ and kinetics ${ }^{11-16}$ are well known. Ueda et al. ${ }^{17}$ carried out systematic studies on high molecular weight nylon 6 and obtained high molecular weight polymer (the weight average molecular weight, $M_{w}=9.5 \times 10^{5}$ ) by controlling water content in monomer and concentration of the catalyst and chain initiator.

Since nylon 6 synthesized by the anionic polymerization of $\varepsilon$-caprolactam shows polymer degradation, anionic polymerization has not been applicable to industrial production. The degradation is caused by the anionic catalyst residue. ${ }^{1,18-22}$ Many researchers have extensively studied the problem from the point of stabilizers for the polymer. ${ }^{23-25}$ However, there is no study showing how to prevent polymer degradation efficiently.

This paper describes a method to prevent polymer degradation by removing the catalyst residue to obtain a stable high-molecular weight nylon 6 . The mechanism of degradation for high-molecular weight nylon 6 is discussed in terms of hydrolysis and catalytic activity of the end carboxyl group.

\section{EXPERIMENTAL}

\section{Materials}

Nylon 6 was synthesized by the anionic polymerization of $\varepsilon$-caprolactam with water content $20 \mathrm{ppm}$ using various concentrations of chain initiator $N$-acetyl- $\varepsilon$ caprolactam (Ac-CL) and two concentrations of the catalyst ethyl magnesium bromide $(\mathrm{EtMgBr} ; 0.5$ or $0.1 \mathrm{~mol} \%$ ) at $150^{\circ} \mathrm{C}^{17}$ Dimethyl sulfoxide (DMSO) was dried till water content was reduced to less than $100 \mathrm{ppm}$ by bubbling $\mathrm{N}_{2}$ gas at $110^{\circ} \mathrm{C}$. Other all chemicals were of reagent grade and used without further purification.

\section{Removal of Catalyst Residue}

Removal of the catalyst residue from the polymer was carried out as follows. The polymer was dissolved in DMSO at $150^{\circ} \mathrm{C}$ under $\mathrm{N}_{2}$ (concentration of polymer is about $5 \mathrm{wt} \%$ ). The acid was added to the polymer solution via a syringe and stired for 2 hours at $150^{\circ} \mathrm{C}$. The solution was poured into a large quantity of methanol for reprecipitation. The polymer reprecipitated was dried, and the DMSO residue in the polymer was removed by boiling water so as not to influence the stability of the polymer. This is the "CR treatment."

\section{Evaluation of Stability of Polymer}

The stability of the polymer was evaluated by change in molecular weight before and after heat treatment. The polymer was dried at $100^{\circ} \mathrm{C}$ for 15 hours under vacuum beforehand. Heat treatment was carried out at 175 $250^{\circ} \mathrm{C}$ (thermostated at $\pm 1.0^{\circ} \mathrm{C}$ ) in an ampoule (diameter $8 \mathrm{~mm}$, volume $3 \mathrm{ml})$ sealed under vacuum $(20$ $\mathrm{Pa})$. The molecular weight of the polymer was evaluated from intrinsic viscosity ([ $\eta]$ measured in $96 \%$ sulfuric acid, less than $0.2 \mathrm{~g} \mathrm{dL}^{-1}$, at $25^{\circ} \mathrm{C}$ ) and weight average molecular weight $\left(M_{w}\right)$ was calculated using eq $1^{17,26}$

$$
M_{w}=2.81 \times 10^{4} \times[\eta]^{1.35}
$$

\section{Analysis}

The concentration of $\mathrm{Mg}$ in the polymer was measured by Inductively Coupled Plasma-Atomic Emission Spectroscopy (ICP; Jarrell-Ash ICAP-575-II). Analysis of the polymer chain end was carried out by NMR (JEOL Lambda300WB; ${ }^{1} \mathrm{H}, 300 \mathrm{MHz}$ ) in DMSO- $d_{6}$ solution at $150^{\circ} \mathrm{C}$.

\section{RESULTS AND DISCUSSION}

\section{Removal of Catalyst Residue}

The degradation of nylon 6 occurs by the anionic catalyst residue. ${ }^{1,18-22}$ Removal of the catalyst residue 


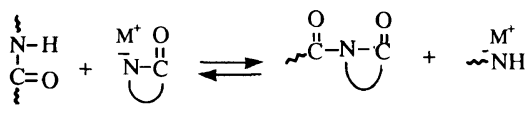

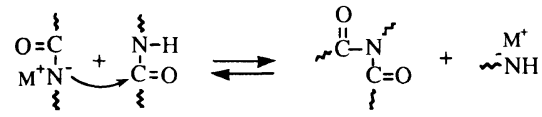

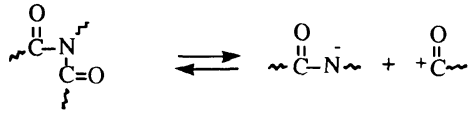

Scheme 1. Mechanism of degradation. ${ }^{1,3,27} \mathrm{M}$ stands for catalyst residue $(\mathrm{MgBr}$ in this study).

$$
\begin{aligned}
& \underset{m \mathrm{~N}-\mathrm{C} m}{\mathrm{M}^{+} \mathrm{O}}+\mathrm{HX} \rightleftharpoons \underset{m \mathrm{~N}-\mathrm{C} m}{\stackrel{H}{1} \mathrm{O}^{\mathrm{O}}}+\mathrm{MX}
\end{aligned}
$$

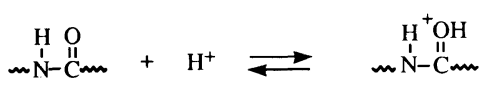

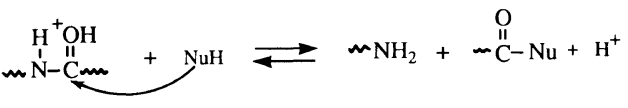

Scheme 2. Mechanism for the reaction of polymer with acid. M stands for catalyst residue $(\mathrm{MgBr}$ in this study). $\mathrm{HX}$ stands for acid (such as acetic acid, sulfuric acid, etc.).

is the most effective method to prevent polymer degradation peculiar to anionic polymerization. The degradation mechanism is shown in Scheme $1^{1,3,27} \mathrm{Re}$ moval of the catalyst residue can be carried out following eq $\mathrm{i}$ in Scheme 2 using acid HX (such as acetic acid, succin-imide, caprolactam, benzyl alcohol, sulfuric acid, etc.). At the same time, acid degradation such as eq ii and iii in Scheme 2 may proceed. Acidity, which changes $\mathrm{N}^{-} \mathrm{M}^{+}$to $\mathrm{NH}$ and does not cause reactions of eq ii and iii in Scheme 2, is necessary to remove the catalyst residue efficiently. We used $\mathrm{p} K_{\mathrm{a}}$ in water $\left(25^{\circ} \mathrm{C}\right)^{3,28,29}$ as measure of acidity. To find an effective acid which can ideally remove the catalyst residue, we studied the relation between $\mathrm{p} K_{\mathrm{a}}$ of the acid in water and capability to remove the catalyst residue.

Figure 1 shows the relation between the concentration of the catalyst residue in nylon 6 with CR treatment and $\mathrm{p} K_{\mathrm{a}}$ in water of various acids, which are sulfuric acid, acetic acid, succin-imide, caprolactam, and benzyl alcohol. The polymer was synthesized with $0.5 \mathrm{~mol} \%$ EtMgBr. Concentrations of the acids were $5 \mathrm{~mol} \%$ (10 times the catalyst concentration) or $50 \mathrm{~mol} \%$ (100 times the catalyst concentration). The concentration of the catalyst residue in nylon 6 was evaluated using $\mathrm{Mg}$ concentration obtained by ICP before and after CR treatment. The concentration of the catalyst residue in nylon 6 decreased as $\mathrm{p} K_{\mathrm{a}}$ of acid decreased. Acids having higher $\mathrm{p} K_{\mathrm{a}}$ than 9 can not efficiently remove the catalyst residue even at high concentration. Acids having smaller $\mathrm{p} K_{\mathrm{a}}$ than 7 efficiently removed the catalyst residue. Strong acid such as sulfuric acid caused gelation or acid degradation of the polymer.

Polymer degradation may thus be inhibited by $\mathrm{CR}$

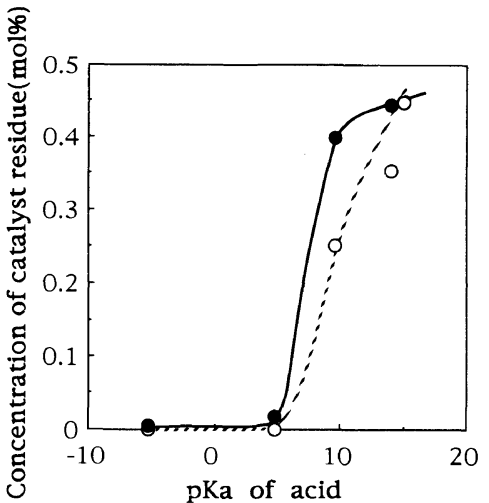

Figure 1. $\mathrm{p} K_{\mathrm{a}}$ of acids versus concentration of catalyst residue in nylon 6 . The removal of the catalyst residue in the polymer was carried out with CR treatment; $(O)$ acid concentration in $5.0 \mathrm{~mol} \%$ and $(O)$ $50 \mathrm{~mol} \%$.

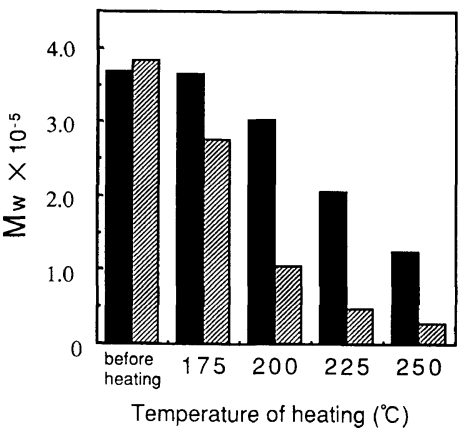

Figure 2. Relation between $M_{w}$ of the polymer after heating and heating temperature about the polymers with CR treatment ( $\square$ ) and

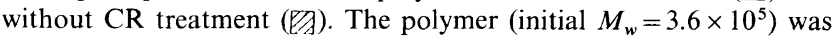
heated for 24 hours.

treatment using the acid whose $\mathrm{p} K_{\mathrm{a}}$ is between 3 and 7 . We chose acetic acid as a reagent to remove the catalyst residue from the polymer, and investigated changes of molecular weight of the polymer at various temperatures.

\section{Polymer Stability at Various Temperatures}

The stability of the polymer at various temperatures was studied. Figure 2 shows the change of $M_{w}$ of the polymer on CR treatment using acetic acid ( $5 \mathrm{~mol} \%$ ) after heating at each heating temperature for 24 hours. Initial $M_{w}$ of the polymer was $3.8 \times 10^{5} \quad([\eta]=6.9)$, which was synthesized with $0.5 \mathrm{~mol} \% \mathrm{EtMgBr}$. Mw of the polymer without CR treatment decreased even at $175^{\circ} \mathrm{C}$, and the decrease of $M_{w}$ was remarkable above $200^{\circ} \mathrm{C}$. $M_{w}$ of the polymer with CR treatment does not decrease at $175^{\circ} \mathrm{C}$. Above $200^{\circ} \mathrm{C}, M_{w}$ of the polymer with CR treatment decreases gradually. The molecular weight of those polymers is much higher than that without $\mathrm{CR}$ treatment above the melting point of nylon 6. Figure 3 shows Arrhenius plots of the reciprocal of time versus log-rate constant $(k)$ of degradation at the first stage on heating. The rate constant is evaluated by the slope of the plots between the time and number of cut bonds per monomer unit $(N)$ calculated by eq 2 .

$$
N=\left(1 / M_{w}^{* *}-1 / M_{w}^{*}\right) \times P \times M
$$

Here, $M_{w}^{* *}$ is $M_{w}$ of the polymer after heating, $M_{w}^{*}$ is that before heating, $P$ is polydispersity $\left(P=M_{w} / M_{n}\right)$, 


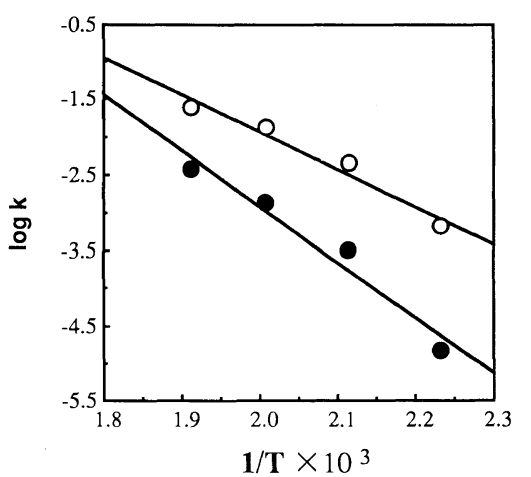

Figure 3. Arrhenius plots of the reciprocal of time versus log-rate constant $(k)$ of degradation of the polymers with CR treatment $(\boldsymbol{O})$ and without $\mathrm{CR}$ treatment $(\mathrm{O})$ at the first stage on heating.

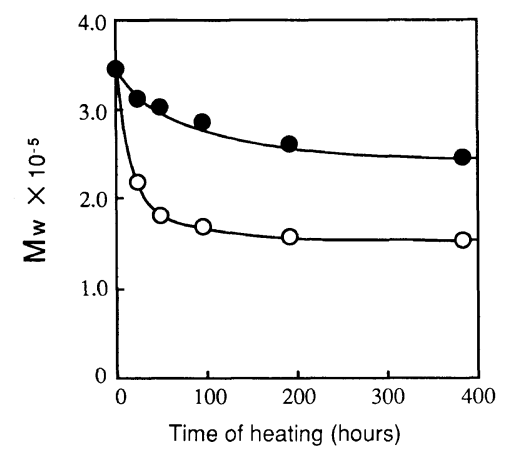

Figure 4. Change of $M_{w}$ of the polymer with CR treatment (o catalyst residue $0.001 \mathrm{~mol} \%$ ) and without $\mathrm{CR}$ treatment $(\mathrm{O})$ on heating at $200^{\circ} \mathrm{C}$. The polymer was synthesized with $0.1 \mathrm{~mol} \% \mathrm{EtMgBr}$ (initial $\left.M_{w}=3.5 \times 10^{5}\right)$.

estimated as 1.9 by GPC and $M$ is molecular weight of the monomer unit. The activation energy of cutting the bond is $94.4 \mathrm{~kJ} \mathrm{~mol}^{-1}$ (without CR treatment) or $141.3 \mathrm{~kJ} \mathrm{~mol}^{-1}$ (with CR treatment).

This catalyst removal method is very efficient and preserves the stability of the polymer over a wide range of temperature.

\section{Improvement Stability for Long-Time Heating}

Long-time stability of the polymer treated with acetic acid $(5 \mathrm{~mol} \%)$ was studied in terms of concentration of catalyst $(0.1$ and $0.5 \mathrm{~mol} \%)$ at the polymerization. Figure 4 shows the change of $M_{w}$ of the polymer on heating at $200^{\circ} \mathrm{C}$. Initial $M_{w}$ of the polymer was $3.5 \times 10^{5}([\eta]=6.4)$, which was synthesized with $0.1 \mathrm{~mol} \%$ EtMgBr. The molecular weights of polymers both with $\mathrm{CR}$ treatment and without CR treatment decreased with time of heating. The curves were asymptotic and reached equilibrium values. The decrease of $M_{w}$ of the polymer without $\mathrm{CR}$ treatment is so considerable as to reach only $M_{w}=1.5 \times 10^{5} . M_{w}$ of the polymer with CR treatment decreases to $2.5 \times 10^{5}$. This value is markedly larger than that of the polymer without CR treatment. The asymptotic value of molecular weight of polymers is explained in the following section. The molecular weight of the polymer reprecipitated was confirmed to be almost the same after CR treatment by viscosity measurement, and the residue of acetic acid and DMSO in the polymer was less than about $10 \mathrm{ppm}$ by NMR measurement. The concentrations of $\mathrm{Mg}$ and $\mathrm{Br}$ in the polymer after $\mathrm{CR}$ treatment were $3 \mathrm{ppm}(0.001 \mathrm{~mol} \%)$ and less than 1086

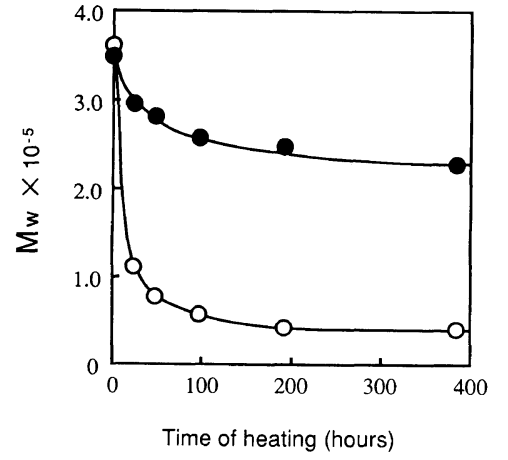

Figure 5. Change of $M_{w}$ of the polymer on heating at $200^{\circ} \mathrm{C}$ with $\mathrm{CR}$ treatment $(O$, catalyst residue $0.001 \mathrm{~mol} \%$ ) and without $\mathrm{CR}$ treatment $(\bigcirc)$. The polymer was synthesized with $0.5 \mathrm{~mol} \% \mathrm{EtMgBr}$ (initial $M_{w}=3.6 \times 10^{5}$ ).

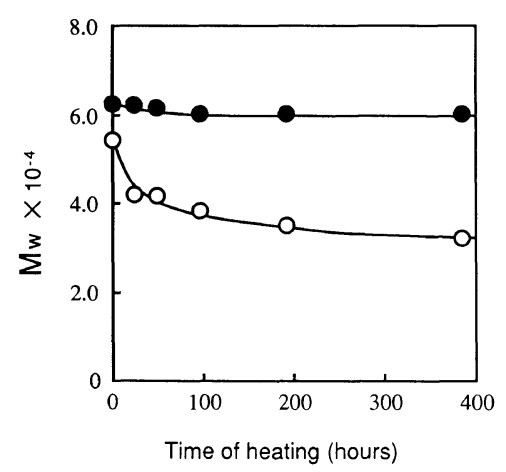

Figure 6. Change of $M_{w}$ of the polymer on heating at $200^{\circ} \mathrm{C}$ with CR treatment (O, catalyst residue $0.001 \mathrm{~mol} \%$ ) and without $\mathrm{CR}$ treatment $(\bigcirc)$. The polymer was synthesized with $0.5 \mathrm{~mol} \% \mathrm{EtMgBr}$ (initial $M_{w}=6.2 \times 10^{4}$ ).

\section{$10 \mathrm{ppm}$, respectively.}

Figure 5 also shows the change of $M_{w}$ of the polymer on heating at $200^{\circ} \mathrm{C}$. Initial $M_{w}$ of the polymer was $3.6 \times 10^{5}([\eta]=6.6)$, which was synthesized with 0.5 mol\% EtMgBr. The results with $\mathrm{CR}$ treatment are similar to those of Figure 4. Reached $M_{w}$ of the polymer with $\mathrm{CR}$ treatment is $2.3 \times 10^{5}$, which agrees with the value $\left(2.5 \times 10^{5}\right)$ of $0.1 \mathrm{~mol} \%$ catalyst. The decrease of $M_{w}$ of the polymer without CR treatment is so remarkable as to reach only $M_{w}=4.0 \times 10^{4}$, which is much lower than the value $\left(1.5 \times 10^{5}\right)$ of $0.1 \mathrm{~mol} \%$ catalyst. This means that the molecular weight of the polymer decreases as the concentration of the catalyst residue increases. Therefore, decrease of the molecular weight of the polymer without CR treatment is caused by the catalyst residue.

The stability of low and high molecular weight polymers $\left(M_{w}=6.2 \times 10^{4}\right.$ and $\left.7.0 \times 10^{5}\right)$ were studied. Figure 6 shows changes of $M_{w}$ of the polymer on heating at $200^{\circ} \mathrm{C}$. Initial $M_{w}$ was $6.2 \times 10^{4}([\eta]=1.8)$, which was synthesized with $0.5 \mathrm{~mol} \%$ EtMgBr. The molecular weight of the polymer with CR treatment using acetic acid has good stability on heating. That without CR treatment markedly decreases, as also in the case of Figure 4. The difference of the initial $M_{w}$ of the polymer between with CR treatment and without CR treatment is due to reprecipitation. The low molecular weight polymer with $\mathrm{CR}$ treatment is highly stable against heating at $200^{\circ} \mathrm{C}$.

The stability of high-molecular weight nylon 6 


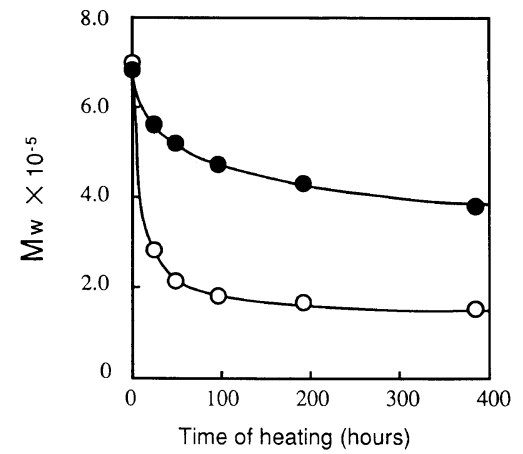

Figure 7. Change of $M_{w}$ of the polymer on heating at $200^{\circ} \mathrm{C}$ with CR treatment $(O$, catalyst residue $0.001 \mathrm{~mol} \%$ ) and without $\mathrm{CR}$ treatment $(\bigcirc)$. The polymer was synthesized with $0.1 \mathrm{~mol} \% \mathrm{EtMgBr}$ (initial $M_{w}=7.0 \times 10^{5}$ ).

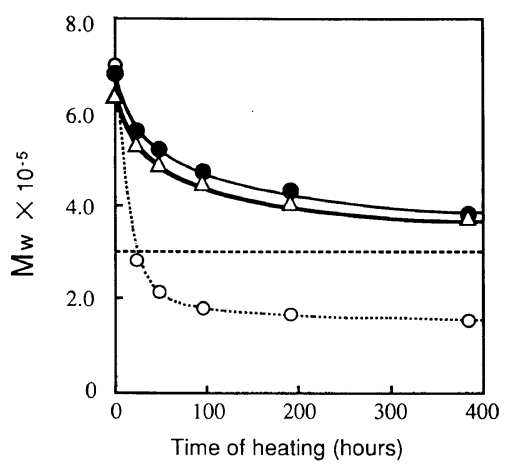

Figure 8. Change of $M_{w}$ of the polymer on heating at $200^{\circ} \mathrm{C}$ with CR treatment (, catalyst residue $0.001 \mathrm{~mol} \%$ ), with CR treatment and with the end capping $(\triangle$, catalyst residue $0.001 \mathrm{~mol} \%$ ), and without $\mathrm{CR}$ treatment $(\mathrm{O})$. The polymer was synthesized with $0.1 \mathrm{~mol} \%$ EtMgBr (initial $M_{w}=7.0 \times 10^{5}$ ). The dotted straight line (--) is the calculated $M_{w}$ at equilibrium state at $200^{\circ} \mathrm{C}$.

$\left(M_{w}=7.0 \times 10^{5}([\eta]=11.2)\right)$ was studied. CR treatment with acetic acid was applied to the high-molecular weight polymer synthesized with $0.1 \mathrm{~mol} \% \mathrm{EtMgBr} .{ }^{17}$ Figure 7 shows the change of $M_{w}$ of the polymer on heating at $200^{\circ} \mathrm{C}$. The decrease of $M_{w}$ is similar to Figure $4 . M_{w}$ of the polymer without $\mathrm{CR}$ treatment decreases to $1.7 \times 10^{5}$ $([\eta]=3.7)$, and that with CR treatment is kept $3.9 \times 10^{5}$ $([\eta]=7.0)$. Thus, the catalyst residue is efficiently removed by adding acetic acid in DMSO solution and the stability of nylon 6 synthesized by the anionic polymerization is improved.

\section{Contribution of Hydrolytic Degradation}

The decrease of molecular weight of nylon 6 caused by the catalyst residue is inhibited by removing the catalyst residue with adding acetic acid in DMSO solution. However, the decrease of molecular weight of the polymer without the catalyst residue is still observed for high-molecular weight nylon 6 . The decrease is caused by hydrolysis with a slight amount of water in the polymer.

The dotted straight lines in Figures 8 and 9 indicate calculated $M_{w}$ at equilibrium state at $200^{\circ} \mathrm{C}$ assuming eq $\mathrm{i}-\mathrm{ix}$ in Scheme $3 .^{30,31}$ Here, $z, w, c$, and $a$ are the concentrations of the amide group, water, carboxyl group, and amino group calculated from $M_{w}$ before heating, respectively; $K$ is the equilibrium constant; $k$ is the rate constant; $\Delta S$ is the change in entropy; $\Delta H$ is the change in enthalpy; $T$ is temperature; $R$ is gas constant;

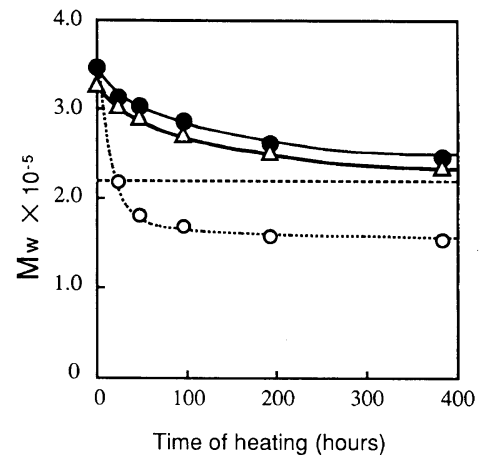

Figure 9. Change of $M_{w}$ of the polymer on heating at $200^{\circ} \mathrm{C}$ with CR treatment ( $O$, catalyst residue $0.001 \mathrm{~mol} \%$ ), with $\mathrm{CR}$ treatment and with the end capping $(\triangle$, catalyst residue $0.001 \mathrm{~mol} \%$ ), and without CR treatment $(O)$. The polymer was synthesized with 0.1 mol\% EtMgBr (initial $M_{w}=3.5 \times 10^{5}$ ). The dotted straight line (---) is the calculated $M_{w}$ at equilibrium state at $200^{\circ} \mathrm{C}$.

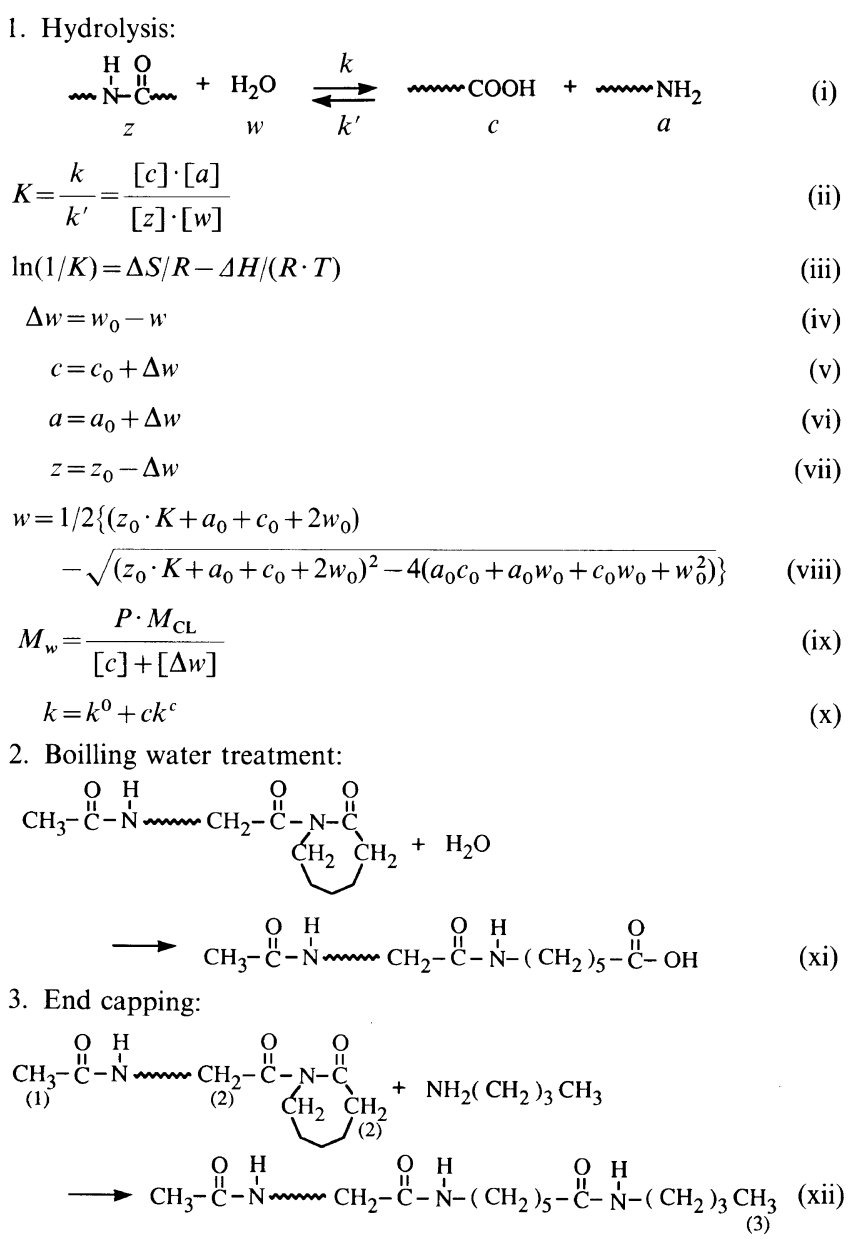

Scheme 3. Reactions and kinetics. ${ }^{1,32}$

the subscript 0 means the initial concentration; $P$ means polydispersity; $M_{\mathrm{CL}}{ }^{17}$ is molecular weight of $\varepsilon$-caprolactam. $M_{w}$ at equilibrium state at $200^{\circ} \mathrm{C}$ is calculated from the change of $w$ assuming that hydrolysis occurs even in the solid state following eq $\mathrm{i}$ in Scheme 3 . The concentration of water at equilibrium state was calculated from eq viii in Scheme 3 in terms of $K$ expressed by $\Delta S$ and $\Delta H$ (eq iii in Scheme 3 ). ${ }^{32}$ We used the following values, $a_{0}=0, c_{0}=0.03 \mathrm{~mol} \%$ (Figure 8 ) or $0.07 \mathrm{~mol} \%$ (Figure 9), $z_{0}=100 \mathrm{~mol} \%$ and $w_{0}=0.1 \mathrm{~mol} \%$, $\Delta S=0.9437$ e.u., $\Delta H=-5945.8 \mathrm{cal} \mathrm{mol}^{-1},{ }^{32} T=473 \mathrm{~K}$. 
These values are based on the assumption that the anionic polymerization proceeds ideally. As shown in Figure 8 (initial $M_{w}$ is $7.0 \times 10^{5}([\eta]=11.2)$ ) and Figure 9 (initial $M_{w}$ is $\left.3.5 \times 10^{5} \quad([\eta]=6.4)\right)$, the stability curves of polymers without the catalyst residue seem asymptotic to the calculated equilibrium $M_{w}$. The decrease of molecular weight of polymers without the catalyst residue thus appears to hydrolysis, not catalyst residue. The asymptotic value in Figures $4-7$ is explained by the assumption that the equilibrium of hydrolysis is reached. The reason, why the low molecular weight polymer with CR treatment is highly stable, is considered that the molecular number of water against the molecular number of the polymer is relatively less for the low molecular weight polymer than for the high molecular weight polymer. It is important that water content in the polymer is reduced to keep the molecular weight.

\section{Influence of End-Capping of Carboxyl Group}

Not to accelerate the reaction rate of hydrolysis, the studies on the end capping of the terminal carboxyl group were carried out, and the stabilization of the end capped polymer was observed. The terminal group of the polymer used for the stability test in the preceding sections is a carboxyl group such as eq xi in Scheme 3 for boilling water treatment. ${ }^{21}$ It is estimated that the carboxyl group acts as catalyst of hydrolysis.

The influence of the chain terminal carboxyl group on stability was studied for the polymer with end capping and without end capping. End capping occurs by $n$ butylamine following eq xii in Scheme 3, since the end of the polymer synthesized by the anionic polymerization without boilling water treatment is the acyllactam group, and the acyllactam end group is opened by boiling water $^{21}$ or amine. ${ }^{33}$ Quantitative evaluation of the endcapping was made by NMR using the low molecular weight nylon 6 as the model compound. The model polymer was synthesized with $2.0 \mathrm{~mol} \% \mathrm{Ac}-\mathrm{CL}$ and $0.1 \mathrm{~mol} \% \mathrm{EtMgBr}$, and $M_{w}$ of the polymer was $9.2 \times 10^{3}$. End capping was carried out by immersing the polymer in excess $n$-butylamine at $78^{\circ} \mathrm{C}$.

The results of end capping are as follows; the ratio of the acetyl group (calculated with (1) in eq xii in Scheme $3 ; 1.8 \mathrm{ppm}$ ) and end methyl group (calculated with (3) in eq xii in Scheme $3 ; 0.9 \mathrm{ppm}$ ) of the polymer with the end capping was 1:0.98, and the $\alpha$-methylene group (calculated with (2) in eq xii in Scheme $3 ; 2.35 \mathrm{ppm}$ ) of the polymer with the end capping was reduced to only $0.4 \mathrm{~mol} \%$ compared with the polymer without the end capping. Consequently, the end capping of the polymer with $n$-butylamine was carried out stoichiometrically. However the end capping reaction of both low and high molecular weight polymer occurs in the same way, the reaction of high molecular weight polymer $\left(M_{w}>10^{5}\right)$ was carried out for long time, since the reaction rate of high molecular weight polymer becomes slower than that of low molecular weight polymer. ${ }^{34}$

Effects of the end capping were studied in terms of stability of the polymer and the results are shown in Figures 8 and 9 . Figure 8 shows change of $M_{w}$ of the polymer (initial $M_{w}$ is $7.0 \times 10^{5}([\eta]=11.2)$ ) on heating. Figure 9 shows the change of $M_{w}$ of the polymer (initial $M_{w}$ is $\left.3.5 \times 10^{5}([\eta]=6.4)\right)$ on heating. The terminal carboxyl group shows neither the catalytic activity foward hydrolysis nor influences the stability of the polymer.

The rate constant $k$ of the hydrolysis was calculated at various concentrations of the carboxyl end group following eq $\mathrm{x}$ in Scheme $3 .^{32}$ Here, $k^{0}$ is the rate constant of the uncatalyzed reaction by the carboxyl end group and $k^{\mathrm{c}}$ is that of catalyzed reaction by the carboxyl end group. The following values were obtained; $k\left(c_{0}=\right.$ $0 \mathrm{~mol} \%)=0.335 \quad\left(\mathrm{~kg} \mathrm{~mol}^{-1} \mathrm{~h}^{-1}\right), \quad k\left(c_{0}=0.03 \mathrm{~mol} \%\right)=$ $0.344\left(\mathrm{~kg} \mathrm{~mol}^{-1} \mathrm{~h}^{-1}\right), \quad k\left(c_{0}=0.07 \mathrm{~mol} \%\right)=0.356 \quad(\mathrm{~kg}$ $\left.\mathrm{mol}^{-1} \mathrm{~h}^{-1}\right)$, and $k\left(c_{0}=0.7 \mathrm{~mol} \%\right)=0.546\left(\mathrm{~kg} \mathrm{~mol}^{-1} \mathrm{~h}^{-1}\right)$. The rate constant $k$ does not significantly change below $0.07 \mathrm{~mol} \%$ of the carboxyl group concentration, which agrees with the experimental results of the end capping of terminal carboxyl group.

The decrease of molecular weight of the polymer without the catalyst residue is thus due to hydrolysis, and improving the stability of the high-molecular weight polymer is achieved by controlling hydrolysis with a slight amount of water in the polymer.

\section{CONCLUSIONS}

To obtain a thermally stable high-molecular weight nylon 6 synthesized by anionic polymerization of $\varepsilon$-caprolactam, the method for inhibiting decrease of molecular weight of the polymer by removing the catalyst residue was established. The catalyst residue in the polymer was efficiently removed by adding acetic acid to dimethyl sulfoxide solution. The stability of the polymer without the catalyst residue was improved. The low molecular weight polymer $\left(M_{w}<10^{5}\right)$ without the catalyst residue was highly stable against heating. The decrease of molecular weight of high-molecular weight polymer $\left(M_{w}>\right.$ $10^{5}$ ) without the catalyst residue was due to the hydrolysis. The rate of polymer degradation was not influenced by the end capping of terminal carboxyl group. To improve the stability of the high-molecular weight polymer for industrial use, hydrolysis must be controlled with a slight amount of water in the polymer.

\section{REFERENCES}

1. J. Sebenda, in "Comprehensive Chemical Kinetics," Vol.15, C. H. Bamfordand and C. F. H. Tipper, Ed., Elsevier, Amsterdam, 1976, Chapter 6.

2. H. Sekiguchi, in "Ring-opening Polymerization," Vol. 2, K. J. Ivin and T. Saegusaed, Ed., Elsevier, London, 1984, p 832.

3. J. Sebenda, in "Comprehensive Polymer Science," Vol. 3, C. F. H. Tipper and C. H. Bamford, Ed., Pergamon Press, Oxford, 1988.

4. R. Puffr, in "Lactam-Based Polyamides," Vol. 1, R. Puffr and V. Kubánek, Ed., CRC Press, Boca Raton, Florida, 1991, vol1.

5. J. Karger-Kocsis and L. Kiss, J. Polym. Sci., Polym. Symp., 69, 67 (1981).

6. R. Puffr and N. Vladimirov, Makromol. Chem., 194, 1765 (1993).

7. J. Sebenda, J. Macromol. Sci., Chem., A6, 1145 (1972).

8. H. Sekiguchi and B. Coutin, J. Polym. Sci., Chem. Ed., 11, 1601 (1973).

9. T. M. Frunze, V. A. Kotel'nikov, T. V. Volkova, and V. V. Kurashev, Eur. Polym. J., 17, 1079 (1981).

10. N. Mougin, C. A. Veith, R. E. Cohen, and Y. Gnanou, Macromolecules, 25, 2004 (1992).

11. E. Sittler and J. Sebenda, Collect. Czech. Chem. Commun., 33, 270 (1968).

12. E. Sittler and J. Sebenda, Collect. Czech. Chem. Commun., 33, 
3182 (1968).

13. J. Stehlicek and J. Sebenda, Eur. Polym. J., 22, 769 (1986).

14. T. M. Frunze, S. P. Davtyan, V. A. Kotel'nikov, T. V. Volkova, and V. V. Kurashev, Vysokomol. Soedin. Ser. B, 23, 388 (1981).

15. V. G. Frolov, Vysokomol. Soedin. Ser. B, 25, 134 (1983).

16. J. Stehlicek and R. Puffr, Macromol. Chem, 193, 2539 (1992).

17. K. Ueda, K. Yamada, M. Nakai, T. Matsuda, M. Hosoda, and K. Tai, Polym. J., 28, 446 (1996)

18. F. Fiala and J. Kralicek, Collect. Czech. Chem. Commun., 40, 1155 (1975)

19. F. Fiala and J. Kralicek, Eur. Polym. J., 12, 155 (1976).

20. J. Stehlicek, B. Valter and J. Sebenda, Macromol. Chem, 187, 513 (1986).

21. J. Sebenda and B. Lanska, J. Macromol. Sci., Pure Appl. Chem., A30, 669 (1993).

22. В. А. Котедьников, Л. Ђ. Данилевская, В. В. Курашев, И. О. Конова, В. В. Гавриленко, and Л. А. Чекулаева, Vysokomol. Soedin. Ser. A, 35, 1257 (1993).

23. M. Pianson and P. Potam, Jpn. Kokoku Tokkyo Koho, JP56-9541 (1981).

24. S. Arakawa, K. Matsuya, Y. Kobayashi, M. Matsushita, and T.
Tsukamoto, Jpn. Kokoku Tokkyo Koho, JP47-40859 (1972).

25. S. Arakawa, K. Matsuya, Y. Kobayashi, M. Matsushita, and T. Tsukamoto, Jpn. Kokoku Tokkyo Koho JP47-40549 (1972).

26. K. Ueda, K. Hattori, M. Nakai, and K. Tai, to be published.

27. J. H. Saunders and F. Dobinson, in "Comprehensive Chemical Kinetics," Vol. 15, C. H. Bamfordand and C. F. H. Tipper, Ed., Elsevier, Amsterdam, 1976, Chapter 7.

28. S. Takahashi, L. A. Cohen, H. K. Miller, and E. G. Peake, $J$. Org. Chem., 36, 1205 (1971).

29. S. H. Pine, "Organic Chemistry," 5th ed., McGraw-Hill, New York N.Y., 1987.

30. K. Tai and T. Tagawa, Ind. Eng. Chem. Prod. Res. Dev., 22, 2 (1983).

31. H. K. Reimschuessel, J. Polym. Sci., Macromol. Rev., 12, 65 (1977).

32. K. Tai, H. Teranishi, Y. Arai, and T. Tagawa, J. Appl. Polym. Sci., 25, 77 (1980).

33. K. Hashimoto, T. Sugata, S. Imanishi, and M. Okada, J. Polym. Sci., A, Polym. Chem., 32, 1619 (1994).

34. G. Montaudo, C. Puglisi, and F. Samperi, J. Polym. Sci., A, Polym. Chem., 32, 15 (1994). 